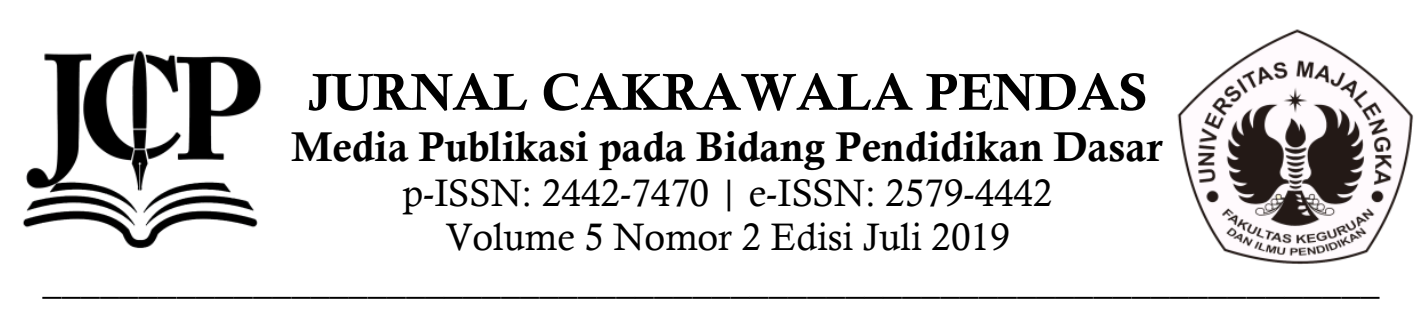

\title{
Keterampilan Matematika Di Abad 21
}

\author{
Dede Salim Nahdi \\ Universitas Majalengka \\ salimnahdi15@gmail.com
}

\begin{abstract}
One of the great challenges of Indonesian society in the 21st Century is globalization. Globalization can lead to greater competition in all areas of people's lives. Basic reading, writing and numeracy skills are no longer sufficient to compete in the 21st Century, which is full of challenges. Education must be able to prepare students to compete in the global community. Every person who lives in the 21st Century must have at least 4 skills, namely critical thinking skills, creative thinking, communication skills and collaboration skills. Mathematics, as a subject taught at school, plays an important role both in dealing with science and technology. Mathematics has a great potential that can equip students to face competition. The great role of mathematics as a basic science, can be seen in the large demands of mathematical skills that must be possessed especially in the face of the 21st Century. Learning mathematics in this Century is required to emphasize the four aspects above as skills that must be possessed in the 21 st century.
\end{abstract}

Keyword: mathematical skills, 21st Century

\begin{abstract}
Abstrak
Salah satu tantangan besar masyarakat Indonesia pada Abad 21 adalah globalisasi. Globalisasi dapat menyebabkan persaingan di segala bidang kehidupan masyarakat semakin besar. Kemampuan dasar membaca, menulis, dan berhitung tidak lagi cukup untuk dapat berkompetisi di Abad 21 yang penuh dengan tantangan. Pendidikan yang dilaksanakan harus mampu menyiapkan para siswa agar dapat berkompetisi di masyarakat global. Setiap orang yang hidup di Abad 21 ini, setidaknya harus memiliki 4 keterampilan yaitu keterampilan berpikir kritis (critical thinking), berpikir kreatif (creative thinking), keterampilan komunikasi (communication), dan keterampilan kolaborasi (collaboration). Matematika, sebagai mata pelajaran yang diajarkan disekolah, memegang peran penting baik dalam menghadapi ilmu dan teknologi. Matematika memiliki sebuah potensi besar yang dapat membekali siswa menghadapi persaingan. Besarnya peranan matematika sebagai ilmu dasar, dapat dilihat pada besarnya tuntutan keterampilan matematis yang harus dimiliki terutama dalam menghadapi Abad 21. Pembelajaran matematika di Abad ini dituntut harus menekankan keempat aspek di atas sebagai keterampilan yang harus dimiliki di abad 21
\end{abstract}

Kata Kunci: keterampilan matematis, Abad 21. 


\section{Pendahuluan}

Perkembangan di bidang ilmu pengetahuan dan teknologi pada Abad 21 telah memberikan konsekuensi pada besarnya tantangan berbeda dari yang pernah dihadapi sebelumnya. Banyak hal yang kemudian berubah di Abad 21 ini, percepatan di bidang ilmu pengetahuan dan teknologi, sistem komunikasi (Toffler, 1992). Abad 21 merupakan periode pengetahuan, suatu periode di mana informasi tersebar secara cepat dan teknologi yang semakin berkembang (Sopian, 2015). Kondisi ini menjadikan dunia seakan-akan semakin sempit, apa yang terjadi di ujung dunia sana, akan dengan depat diketahui oleh orang yang berada di ujung dunia yang lain, dalam waktu yang bersamaan.

Karakteristik Abad 21 ditandai dengan semakin bertautnya dunia ilmu pengetahuan, sehingga sinergi diantara keduanya menjadi semakin cepat (Fakhruddin, Ananda, \& Istiningsih, 2013). Abad 21 juga ditandai dengan tersedianya informasi dimana saja dan kapan saja (informasi), adanya implementasi penggunaan mesin (komputasi), mampu menjangkau segala pekerjaan rutin (otomatisasi) dan komunikasi yang dapat dilakukan dari mana saja dan kemana saja (Litbang Kemdikbud, 2013). Segala perubahan yang begitu cepat begitu cepat mempengaruhi berbagai aspek kehidupan, termasuk pendidikan.

Pendidikan adalah suatu sistem yang selalu mengalami perubahan seiring perubahan jaman dengan segala tuntutannnya. Pada abad 21, segala alternatif usaha untuk memenuhi kebutuhan hidup dalam berbagai konteks lebih berorientasi pada pengetahuan (Mukhdis, 2013). Dalam konteks pemanfaatan teknologi informasi dan komunikasi di dunia pendidikan, pendidikan telah terbukti dengan semakin menyempit dan meleburnya faktor ruang dan waktu yang selama ini menjadi aspek penentu kecepatan dan keberhasilan ilmu pengetahuan (BSNP, 2010). Apa yang dianggap sebagai pendidikan terbaik pada beberapa tahun yang lalu tidak lagi cukup untuk sukses dalam karir dan hidup bermasyarakat di abad ke-21 (The National
Education Association, 2015). Oleh karena itu, pendidikan berkualitas adalah pendidikan yang dapat membekali siswanya dengan keterampilan-keterampilan yang dibutuhkan di abad ini. Semakin baik proses dan hasil pendidikan maka semaik berkualitas system pendidikan yang diterapkan.

Di Indonesia, jika mengacu beberapa hasil studi, sistem pendidikan yang dijalankan belum sesuai dengan hasil yang diharapkan. Merujuk pada data Badan Program Pembangunan di bawah PBB (United Nations Development Programme/UNDP) dalam laporan Human Development Report 2016 mencatat, Indeks Pembangunan Manusia (IPM) Indonesia pada 2015 berada di peringkat 113, turun dari posisi 110 di 2014. UNDP mencatat, IPM Indonesia 2015 sebesar 0,689 dan berada di tingkat 113 dari 188 negara di dunia. Berdasarkan data dalam Education For All (EFA) Global Monitoring Report 2011: "The Hidden Crisis, Armed Conflict and Education" yang dikeluarkan UNESCO, meyebutkan bahwa Indeks Pembangunan Pendidikan Indonesia menurun dari peringkat 65 ke peringkat 69 dari 127 negara, (Majid, 2014). Akibat rendahnya kualitas pendidikan di Indonesia, maka Indonesia memiliki daya saing yang rendah, yaitu hanya menduduki urutan ke37 dari 57 negara yang disurvei di dunia (The World Economic Forum Swedia Report, 2000). Indonesia pun hanya berpredikat sebagai follower bukan sebagai leader teknologi dari 53 negara di dunia.

Kondisi pendidikan yang digambarkan di atas tentunya sangat memprihatinkan. Menjadi tugas berat bagi bangsa Indonesia dalam meningkatkan kualitas pendidikan agar siap menghadapi abad 21. Dibutuhkan keterampilan belajar dan inovasi untuk mempersiapkan siswa dalam kehidupan yang lebih kompleks dan lingkungan kerja di abad 21 (Partnership for $21^{\text {st }}$ Century, 2009)

Matematika merupakan salah satu mata pelajaran diajarkan di semua jenjang pendidikan dan memegang peranan penting dalam pengembangan ilmu dan teknologi. Keterampilan dan pengetahuan matematika sangat penting dalam kehidupan seharihari, pengembangan karir serta landasan 
pengembangan dalam sains dan teknologi (Kaufman, 1979; Garnett, 1998; Ibrahim, 1998; Aziz, 2002; Curriculum Development Centre, 2003; Nik Azis, 2008). Oleh karena itu, matematika dapat dijadikan media dalam mengembangkan keterampilan abad 21. Matematika dapat menjadi tenaga pendukung menyiapkan para siswa agar mampu memecahkan masalah (Nagasaki, 2015). Peran matematika sebagai ilmu dasar, dapat dilihat pada besarnya tuntutan keterampilan matematis yang harus dimiliki terutama dalam menghadapi Abad 21.

\section{Hasil dan Pembahasan}

1. Pendidikan Matematika di Abad 21

Perkembangan dunia Abad 21 ditandai dengan pemanfaatan teknologi informasi dan komunikasi dalam segala segi kehidupan. Segala aktivitas kehidupan yang dilakukan sehari-hari tak lepas dari penggunaan teknologi. Dalam pembelajaran abad ke-21, siswa harus dibekali kemampuan pengarahan diri sendiri dan kemampuan untuk berkolaborasi dengan individu, kelompok, dan mesin (McCoog, 2008). Pendidikan yang dilaksanakan harus mampu menyiapkan para siswa agar dapat berkompetisi di masyarakat global (Murtiyasa, 2016). Tujuannya untuk menyikapi tuntutan zaman yang semakin kompetitif serta terus berkembang. Atas dasar itulah, perlu dipersiapkan karakter keterampilan yang harus dimiliki siswa dalam proses pendidikan menuju abad ke21 bagi seluruh jenjang pendidikan dan semua mata pelajaran, tak terkecuali matematika.

Dewasa ini, setiap proses pembelajaran, termasuk matematika, harus memenuhi aspek masa depan yang ditentukan oleh kebaruan dan pengembangan berkelanjutan (Pearson, 2015). Dengan demikian menjadi sebuah tugas yang tidak mudah bagi setiap guru pengajar matematika dalam membentuk karakter siswanya agar menjadi siswa yang siap dengan tantangan di masa depan.

2. Keterampilan Matematika Abad 21

Dalam menghadapi tantangan Abad 21, setiap orang harus memiliki keterampilan berpikir kritis, pengetahuan dan kemampuan literasi digital, literasi informasi, literasi media dan menguasai teknologi informasi dan komunikasi (Frydenberg \& Andone, 2011). Siswa harus dibekali kemampuan berpikir kritis dan pemecahan masalah mengarah pada kemampuan berpikir secara kritis, lateral, dan sistemik, terutama dalam konteks pemecahan masalah (BSNP, 2010). Kemampuan berkomunikasi dan bekerjasama yakni mampu berkomunikasi dan berkolaborasi secara efektif dengan berbagai pihak. Kemampuan mencipta dan membaharui berkaitan dengan mampunya seseorang dalam mengembangkan kreativitas yang dimilikinya untuk menghasilkan berbagai trobosan yang inovatif. Pembelajaran matematika menurut NCTM (2000) mengharuskan adanya keterampilan memecahkan masalah, menalar dan membuktikan, komunikasi, koneksi, dan representasi sehingga dalam pembelajaran matematika pun berkaitan erat dengan keterampilan abad-21.

Partnership for 21st Century Learning (2015) telah mengembangkan framework pembelajaran di Abad 21 yang menuntut siswa untuk memiliki keterampilan, pengetahuan dan kemampuan dibidang teknologi, media dan informasi, keterampilan pembelajaran dan inovasi serta keterampilan hidup dan karir. Framework ini juga menjelaskan tentang keterampilan, pengetahuan dan keahlian yang harus dikuasai agar siswa dapat sukses dalam kehidupan dan pekerjaanya.

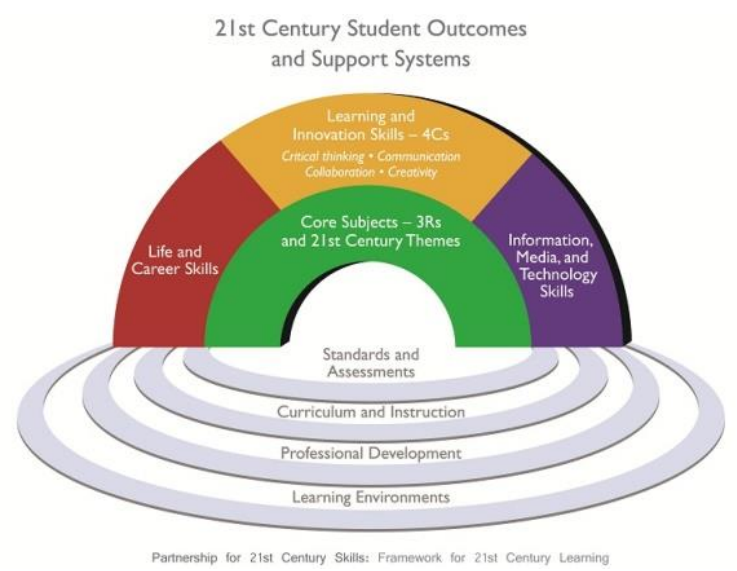

Life and Career skill adalah keterampilan individu untuk hidup dan berkarir, meliputi 
fleksibilitas dan adaptabilitas, inisiatif dan mengatur diri sendiri, interaksi sosial dan budaya, produtivitas dan akuntabilitas, kepemimpinan dan tangggung jawab. Learning and innovation skills-4Cs (keterampilan belajar dan berinovasi) meliputi: 1) Keterampilan berpikir kritis (critical thinking), 2) Keterampilan komunikasi (Communication Skill), 3) Keterampilan kolaboratif (Collaborative Skill) dan 4) Keterampilan berpikir kreatif (Creative Thinking Skill). Information Media and Technologi Skill adalah keterampilan media dan teknologi, meliputi literasi informasi, literasi media dan literasi ICT. Keterampilan abad-21 berfokus pada keterampilan belajar kritis dan inovasi (Trilling \& Fadel, 2009). Keterampilanketerampilan tersebut terdiri dari berpikir kritis dan memecahkan masalah, komunikasi dan kolaborasi, dan kreatif dan inovasi. Sejalan dengan hal itu, Kemdikbud merumuskan bahwa paradigma pembelajaran Abad 21 menekankan pada kemampuan peserta didik dalam mencari tahu dari berbagai sumber, merumuskan permasalahan, berpikir analitis dan kerjasama serta berkolaborasi dalam menyelesaikan masalah (Litbang Kemdikbud, 2013).

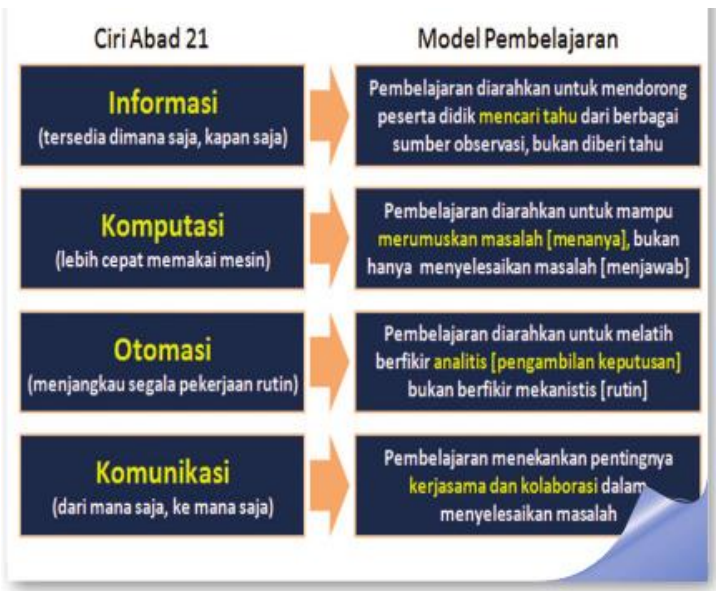

Berdasarkan uraian di atas, dapat disimpulkan bahwa setiap orang yang hidup di Abad 21 ini, setidaknya harus memiliki 4 keterampilan yaitu keterampilan berpikir kritis (critical thinking), berpikir kreatif (creative thinking), keterampilan komunikasi (communication), dan keterampilan kolaborasi (collaboration). Dengan demikian pembelajaran matematika di era Abad 21 dituntut harus menekankan pada empat keterampilan tersebut, sehingga para siswa dapat menggunakan berbagai teknik untuk membuat ide-ide baru yang bermanfaat, merinci, memperbaiki, menganalisis, dan mengevaluasi ide-ide mereka guna mengembangkan dan memaksimalkan usaha kreatif dan mendemonstrasikan keaslian temuan, baik secara individu maupun kelompok.

\section{a. Keterampilan Berpikir Kritis (Critical Thinking Skill)}

Berpikir kritis merupakan suatu sikap berpikir secara mendalam mengenai masalah-masalah yang berada dalam jangkauan pengalaman seseorang (Fisher, 2008). Orang yang mampu berpikir kritis dapat menganalisis, menginterpretasikan, mengevaluasi, dan mesistesakan informasiinformasi yang diperoleh (Sunardi, 2016). Keterampilan berpikir kritis sangat penting dikuasai oleh siswa agar siswa lebih terampil dalam menyusun sebuah argumen, memeriksa kredibilitas sumber, atau membuat keputusan.

Matematika merupakan mata pelajaran yang unik dan terdiri atas unsur-unsur sederhana hingga kompleks. Keunikan dan kompleksitas unsur pada matematika mengharuskan para pembelajar matematika mampu berpikir kritis dalam mempelajari matematika. (Sulistiani, \& Masrukan, 2016). Berpikir kritis dalam matematika dilakukan dengan mengkombinasikan pengetahuan, kemampuan penalaran matematik, dan strategi kognitif sebelumnya, untuk menggeneralisasikan, membuktikan, mengevaluasi situasi matematik secara reflektif (Sumarmo, et. a1., 2016).

Dalam mengembangkan sikap berpikir kritis, siswa harus diberikan permasalahan yang memerlukan kecermatan dan ketelitian dalam memecahkan suatu persoalan matematika. Untuk memecahkannya, siswa harus mampu memahami setiap data yang ada untuk selanjutnya menyusun rencana penyelesaian agar dapat menghasilkan jawaban-jawaban yang tepat dan kesimpulan yang logis. Berpikir Kritis membutuhkan upaya seseorang untuk mengumpulkan, menafsirkan, menganalisis 
dan mengevaluasi informasi untuk tujuan mencapai kesimpulan yang andal dan valid (Chukwuyenum, 2013)Siswa yang memiliki kemampuan berpikir kritis matematis dapat meningkatkan potensi intelektualnya, dan juga rasa percaya diri dalam menyelesaikan persoalan matematika, tidak hanya itu siswa tidak akan takut dan ragu ketika dihadapkan pada masalah nyata dikehidupan sehari-hari.

Berpikir kritis dalam pembelajaran matematika dapat melatih siswa berpartisipasi secara aktif untuk memperoleh dan menemukan pengalamanpengalaman bermakna dalam proses pembelajaran. Akibatnya, siswa terbiasa menghadapi tantangan dan memiliki kemampuan untuk memecahkan masalah, hingga pada akhirnya tercipta sumber daya manusia Indonesia yang unggul dan berkualitas serta siap bersaing menghadapi tantangan

\section{b. Keterampilan Berpikir Kreatif (Creative Thinking Skill)}

Berpikir kreatif dalam matematika merupakan proses menghasilkan solusi kebaruan terhadap suatu permasalahan dan atau menjadikan pendekatan lama menjadi baru (Aizikovitsh, 2014). Berpikir kreatif adalah proses (bukan hasil) untuk menghasilkan ide baru dan ide itu merupakan gabungan dari ide-ide yang sebelumnya belum disatukan (Izzati, 2014). Siswa kreatif berbakat memiliki kemampuan yang tidak biasa untuk menghasilkan sesuatu yang baru dan solusi berguna untuk masalah simulasi atau nyata, menggunakan model matematika (Chamberlain \& Moon, 2005). Melalui kemampuan berpikir kreatif seseorang akan menghasilkan ide baru, serta menemukan banyak kemungkinan jawaban dari suatu masalah.

Siswa harus mampu mempunyai kemampuan untuk mengembangkan dan menyampaikan gagasan baru kepada orang lain, bersikap terbuka untuk menerima perubahan, saran, dan kritik serta responsif terhadap perspektif yang baru dan berbeda. Untuk mengembangkan karakter ini, seorang guru perlu membuka ruang dan kebebasan kepada peserta didik untuk mengembangkan kreativitasnya. Hal ini sebagai langkah untuk mengembangkan bakat dan minat peserta didik. Selain itu, budayakan apresiasi terhadap sekecil apapun peran dan prestasi peserta didik. Langkah ini bertujuan untuk memberi motivasi untuk meningkatkan prestasinya sehingga semangat untuk belajar semakin bertambah.

\section{c. Keterampilan \\ (Communication Skill)}

Komunikasi

Komunikasi menjadi bagian yang tidak terpisahkan dari seluruh aktifitas manusia. Sebagai makhluk sosial yang tidak bisa hidup sendiri tanpa orang lain, komunikasi menjadi hal yang sangatlah penting. Melalui komunikasi, terdapat proses penyampaian ide atau gagasan secara lisan ataupun tulisan sehingga menciptakan pemahaman (Ningrum dan Caswita, 2016; Asnawati, 2017). Ketika siswa ditantang untuk berpikir dan bernalar dan kemudian mengomunikasikan ide-ide mereka secara lisan atau tertulis, pemahaman konseptual yang sejati berkembang (Hirschfeld-Cotton, 2008). Komunikasi dalam matematika merupakan cara untuk berbagi ide dan memperjelas pemahaman pada belajar matematika (Suryadi, 2008). Dengan menggunakan bahasa matematika yang benar untuk berbicara dan menulis tentang apa yang mereka kerjakan, mereka akan mampu mengklarifikasi ide-ide mereka dan belajar bagaimana membuat argument yang meyakinkan dan mempresentasikan ide-ide matematika (Astuti, \& Leonard, 2015).

Komunikasi yang dilakukan oleh siswa khususnya dalam matematika, dapat mengeksplorasi dan mengonsolidasikan pemikiran, serta pengetahuan dan pengembangan dalam memecahkan masalah. Dalam hal ini, komunikasi difokuskan pada dasar-dasar komunikasi yang baik yaitu berbicara, menulis, membaca sebagai kebutuhan hubungan sosial. Peserta didik dituntut untuk memahami, mengelola, dan menciptakan suatu komunikasi yang efektif antar sesama baik dalam bentuk tulisan, lisan, dan multimedia. Peserta didik diberi kesempatan untuk menyampaikan ide, gagasan, dan pendapatnya baik dalam diskusi kelompok maupun dalam berdiskusi dengan gurunya. Kegiatan pembelajaran 
merupakan sarana yang sangat strategis untuk melatih, mengembangkan, dan meningkatkan kemampuan komunikasi peserta didik, baik komunikasi antara peserta didik dengan guru, maupun komunikasi antar sesama peserta didik.

d. Keterampilan Kolaborasi (Collaboration Skill)

Kolaborasi adalah kegiatan bekerjasama dengan orang lain untuk mencapai tujuan bersama (Greinstien, 2012). Keterampilan kolaborasi digambarkan sebagai keterampilan yang mendorong mekanisme pembelajaran, seperti induksi, deduksi, dan pembelajaran asosiatif. Kolaborasi sangat penting dalam pembelajaran karena siswa dapat menggunakan keterampilan tersebut ketika mereka berada di dunia kerja. Selain itu, kolaborasi semakin diidentifikasi sebagai hasil pendidikan yang penting dan merupakan salah satu keterampilan utama abad ke-21 (Boholano, 2017; Pellegrino, 2014). Untuk meningkatkan keterampilan kolaborasi, guru dapat melaksanakan pembelajaran dengan mengelompokkan siswa sehingga mereka belajar secara bersama-sama untuk mengimbangi perbedaan pandangan, pengetahuan, berperan dalam diskusi dengan memberikan saran, mendengarkan, dan mendukung satu sama lain. Pembelajaran matematika haruslah dikemas dalam bentuk kelompok (team work), agar siswa terbiasa dalam bekerja sama, mengemukakan gagasan, menghargai pendapat orang lain, mengambil keputusan dengan tepat dan bijaksana, serta bertanggung jawab terhadap segala keputusan yang telah diambil dalam kelompok.

Siswa dituntut untuk menunjukkan kemampuannya dalam kerja sama secara berkelompok dan kepemimpinan, mampu beradaptasi dalam peran dan tanggung jawab, bekerja secara produktif dalam kelompoknya, menghormati perspektif yang berbeda, serta bersikap empati terhadap sesama. Pembelajaran secara berkelompok melatih peserta didik melakukan kerja sama dan berkolaborasi dalam bekerja. Hal ini sebagai langkah untuk menanamkan kemampuan bersosialisasi dan mengendalikan ego dan emosi sehingga tercipta suasana kebersamaan, rasa memiliki, bertanggung jawab, dan kepedulian antar sesama anggota.

\section{Simpulan}

Dalam menyiapkan generasi di masa depan, maka pendidikan harus menghasil lulusan yang mampu menjawab tantangan yang muncul di waktu yang akan datang. Dengan demikian, pembelajaran yang dilaksanakan guru harus mengembangkan keterampilan yang dibutuhkan di masa depan. Hidup di Abad 21 ini, setidaknya ada empat keterampilan yang harus dimiliki yaitu keterampilan berpikir kritis (critical thinking), berpikir kreatif (creative thinking), keterampilan komunikasi (communication), dan keterampilan kolaborasi (collaboration). Matematika, sebagai ilmu yang diajarkan di setiap jenjang pendidikan, diharapkan dapat memberikan kontribusi signifikan terhadap pembangunan karakter siswa yang siap menghadapi kehidupan global yang terus berkembang pesat di Abad 21 .

\section{Daftar Pustaka}

Aizikovitsh. (2014). The Extent of Mathematical Creativity and Aesthetics in Solving Problems among Students Attending the Mathematically Talented Youth Program. Creative Education,5, 228-241. Retrieved from http://file.scirp.org/pdf/CE_201 4031217160229.pdf

Asnawati, S. (2017). Peningkatan Kemampuan Komunikasi Matematis Siswa Smp Dengan Pembelajaran Kooperatif Tipe Teams-Games-Tournaments. Jurnal Euclid, 3(2), 474-603

Astuti, A. \& Leonard. (2015). Peran Kemampuan Komunikasi Matematika Terhadap Prestasi Belajar Matematika Siswa. Jurnal Formatif, 2(2): 102-110

Aziz, O. (2002). Komunikasi dalam matematik. Jurnal Akademik Maktab Perguruan Terengganu. 12: 41-57.

Boholano, H. (2017). Smart Social Networking: 21st Century Teaching and Learning Skills. 
Research in Pedagogy, 7(1), 21-29, https://doi.org/10.17810/2015. 45

BSNP. (2010). Paradigma Pendidikan Nasional Abad XXI. Jakarta

Chamberlain and Moon (2005) Chamberlin, S. A., \& Moon, S. (2005). Model-Eliciting Activities: An Introduction to Gifted Education. Journal of Secondary Gifted Education, 17, 3747.

Chukwuyenum, N.A. (2013). Impact of Critical thinking on Performance in Mathematics among Senior Secondary School Students in Lagos State. IOSR Journal of Research \& Method in Education (IOSR-JRME), 3(5), 18-25.

Curriculum Development Centre, Ministry of Education Malaysia. (2003). Integrated Curriculum for Secondar School Mathematics Curriculum Specifications. Kuala Lumpur

Dillenbourg, P. (1999). What do you mean by collaborative learning? In $P$. Dillenbourg (Ed.), Collaborativelearning: Cognitive and Computational Approaches. Oxford: Elsevier

Fakhruddin, M. Ananda, R. \& Istiningsih, S. (2013). Perubahan Paradigma Dalam Organisasi Belajar Di Abad 21. Perspektif Ilmu Pendidikan, 27 (2), 110-117.

Fisher, A. (2008). Berpikir Kritis : Sebuah Pengantar. Jakarta: Erlangga.

Frydenberg, M., \& Andone, D. (2011). Learning for 21 st Century Skills, 314-318.

Garnett, K. G. (1998). Maths Learning Disabilities. Journal of CEC. retrieved from http://www.idonline.org/ld_ind epth/math_skill/garnet.html

Goto, J., Batchelor, J., \& Lautenbach, G. (2015). MOOCs for Pre-Service Teachers: Their Notions of 21st Century Learning Design. In ISTAfrica Conference (pp. 1-9).

Hirschfeld- Cotton, K. (2008). Mathematical Communication, Conceptual Understanding, and Students' Attitudes Toward
Mathematics. Action Research Projects. 4.

Hunter, D. (2006). Assessing collaborative learning. British Journal of Music Education, 23(1), 75-89

Ibrahim Ismail. (1998). Matematik dan masyarakat. Jurnal Akademik Maktab Perguruan Kota Bahru, 6: 30-35.

Izzati, N. (2014). Pengaruh Penerapan Model Pembelajaran Berbasis Proyek Terhadap Kemampuan Berpikir Kreatif Mahasiswa. EduMa. Vol. 3 No.1. 77-91.

Kaufman, J. E. (1979). Mathematics is...... Boston: Prindle, Weber \& Schmidt.

Kemdikbud. (n.d.). Jumlah Data Satuan Pendidikan (Sekolah) Per Provinsi. Retrieved from http://referensi.data.kemdikbud. go.id/index11.php

Litbang Kemdikbud. (2013). Kurikulum 2013: Pergeseran Paradigma Belajar Abad-21. Retrieved from http://litbang.kemdikbud.go.id/ index.php/index-beritakurikulum/243-kurikulum-2013pergeseran-paradigma-belajarabad-21.

McCoog, I.J. (2008). 21st Century teachi ng and learning. Education Reso urce Center. Retrieved from eric. ed.gov/PDFS/ED502607.pdf

Mukhdis, A. (2013). Sosok Manusia Indonesia Unggul dan Berkarakter dalam Bidang Teknologi Sebagai Tuntutan Hidup di Era Globalisasi. Jurnal Pendidikan karakter, 3(2), 115-136.

Murtiyasa, B. (2016). Isu-Isu Kunci dan Tren Penelitian Pendidikan Matematika. Makalah. Konferensi Nasional Penelitian Matematika dan Pembelajarannya (KNPMP I) 6 Universitas Muhammadiyah Surakarta.

National Education Association. (2015). Preparing 21st century students for a global society: An educator's guide to the "Four Cs". Retrieved from http://www.nea.org/assets/docs /A-Guide-to-Four-Cs.pdf 
Huda, N., et.al. (2017). Profil Berpikir Kreatif Siswa Dalam Memecahkan Masalah Segitiga Berdasarkan Tingkat Kemampuan Matematis Kelas Vii Smp Negeri 1 Palu. Jurnal Elektronik Pendidikan Matematika Tadulako, hal 383

Nagasaki E. (2015) Mathematical Literacy for Living in the Highly Informationand-Technology-Oriented in the 21st Century: Mathematics Education from the Perspective of Human Life in Society. In: Cho S. (eds) Selected Regular Lectures from the 12th International Congress on Mathematical Education. Springer, Cham

Ningrum, O.D., \& Caswita (2016). Kemampuan komunikasi matematis dengan pembelajaran berbasis inquiri. Prosiding, ISBN: 978 $602-1150-19-1$, hal 748 .

Partnership for 21st Century. (2009). P21 framework definitions: Partnership for 21st Century Skills. Retriewed from

https://files.eric.ed.gov/fulltext/ ED519462.pdf

Partnership for 21st Century. (2015). Framework for 21st Century Learning. Retrieved from http://www.p21.org/storage/do cuments/docs/P21_Framework Definitions_New_Logo_2015.pd $\mathrm{f}$

Pearson (2015). English Learners in 21stcentury classrooms book. In how to teach in 21st century classrooms. Retrieved from ptgmedia.pearsoncmg.com/imag es/9780132685153/samplechapt er/0132685159.pdf

Pellegrino, J. W. (2014). Assessment as a positive influence on 21 st century teaching and learning: A systems approach to progress. Psicologia Educativa, 20(2), 65-77. https://doi.org/10.1016/j.pse.20 14.11 .002

Pinto, A., \& Escudeiro, P. (2014). The Use of Scratch for the Development of 21st Century Learning Skills in ICT. In Information Systems and
Technologies (CISTI), 9th Iberian Conference on (pp. 1-4). Barcelona: IEEE. http://doi.org/10.1109/CISTI.2 014.6877061

Rusyna, Adun (2014). Keterampilan Berpikir. Yogyakarta: Penerbit Ombak.

Sopian, Y. (2015). Pendidikan Abad 21, Retrieved from http://yana.staf.upi.edu/2015/1 0/11/pendidikan-abad-21/

Sumarmo, et. Al. (2012). Kemampuan dan Disposisi Berpikir Logis, Kritis, dan Kreatif Matematik. Jurnal Pengajaran MIPA. 17 (1). 17-33.

Sunardi. (2016). "Strategi Penguatan Pengembangan 4c's Dalam Pembelajaran Matematika". Prosiding Seminar Nasional Pendidikan Matematika. 10-19.

Sulistiani, E. \& Masrukan. (2016). Pentingnya Berpikir Kritis dalam Pembelajaran Matematika untuk Menghadapi Tantangan MEA. Seminar Nasional Matematika $X$ Universitas Negeri Semarang, 605612.

Toffler, A. (1992). Kejutan Masa Depan. Alih bahasa Sri Koesdiyantinah Jakarta: Penerbit Pantja Simpati.

Trilling, B., \& Fadel, C. (2009). 21st Century Skills: Learning for Life in Our Times. San Francisco, CA: John Wiley \& Sons.

Yengin, I. (2014). Using Educational Technology to Create Effective Learning Societies in 21st Century. In Information Technology Based Higher Education and Training (ITHET) (pp. 1 - 7). York:

IEEE. http://doi.org/10.1109/ITHET. 2014.7155689 